\title{
Discovery to E-discovery of Information: Legal Frameworks in Malaysia, the United Kingdom and the United States
}

\author{
Duryana Mohamed \\ Legal Practice Department, AIKOL, IIUM, Malaysia
}

\begin{abstract}
Discovery or disclosure involves a process whereby parties to the action disclose to each other documents in their possession, custody or control as a preparation for trial. This process started in England since the Nineteenth Century. At present the civil procedure in England is governed by the Civil Procedure Rules (CPR) 1998 while in the US the governing rule is the Federal Rule of Civil Procedure (FRCP). In Malaysia the Rules of Court $2012(R C)$ govern the civil procedure at both Subordinate courts and the High courts. The process of discovery of documents is governed by Part 31 of $C P R$, Order 24 of the $R C$ and Rule 34 as well as Rule 26 of the FRCP. However, unlike the CPR and the FRCP the RC has not provided any specific provision or Practice Direction on e-discovery, even with the development in information and communication technology (ICT). This paper will analyse on the process of discovery and e-discovery of information by looking at its legal frameworks in the UK, the United States (US) and Malaysia. The challenges in managing e-discovery and the possible changes that need to be done in Malaysia will also be highlighted.
\end{abstract}

\section{Introduction}

Discovery or disclosure is a pre-trial process which involves both parties in a cause or matter. This process is only adopted when there is a necessity to gather information or documents as to complete one's case ${ }^{\mathrm{i}}$. The aim of discovery process is to find relevant document which is believed to be in the possession, custody or control of the other party. This method is also adopted and applied in order to avoid the element of surprise or trial by ambush. In order to avoid failure in locating relevant information and to avoid million of loses [1] some organisations have adopted electronic discovery (e-discovery) in their practice. This paper will discuss the implementation of e-discovery of electronic stored information (ESI) in the UK, the US and Malaysia, the challenges in managing e-discovery and the possible updates on rule of discovery in Malaysia.

\section{Discovery: Definition and background}

Discovery is defined as "a procedure directed towards obtaining a proper examination and determination of issues". Only a document which relates in some way to a matter in issue is discoverable, but it is sufficient if it would, or would lead to train of inquiry which would, either advance a party's own case or damage that of his adversary" [2].

The above statement implies that fishing expedition is prohibited in discovery process $\mathrm{s}^{\mathrm{ii}}$. The applicant for discovery must only seek for relevant documents which are or have been in the other party's possession, custody or power [3]. If the applicant fails to comply with discovery requirements the court may reject the application for discovery. This happened in $A B X$ Logistics (Malaysia) Sdn Bhd v Overseas Bechtel (Malaysia) $S d n B h d^{i i i}$ where the court dismissed an appeal by the defendant who applied for discovery and held that the application amounted to fishing expedition

Discovery process has been adopted in England since the Nineteenth Century by the English equity procedures. Previously, discovery was governed by the Rules of Supreme Court 1965 (RSC) then it was replaced by the Civil Procedure Rules 1998 (CPR) which came into force in 1999. In Malaysia, prior to 1980 the RSC was the main statute governing civil procedures. This statute was then abolished and replaced by the Rules of High Court 1980 (RHC) and the Subordinate Court Rules 1980 (SCR). The reference to both rules continued until $1^{\text {st }}$ August 2012 when the Rules of Court 2012 (RC) came into force.

Basically, the process of discovery of document in the UK and Malaysia is quite similar except that in the UK discovery is referred to as disclosure and there is specific Practice Direction governing certain part of the rule. Part 31 of the UK Civil Procedure Rules (CPR) provides for disclosure and inspection of document and in Malaysia discovery and inspection of document is mentioned under Order 24 of the Rules of Court 2012(RC). Besides that, discovery procedure is also mentioned under Rule 34 of the US Federal Rule of Civil Procedure (F.R.C.P). This rule is more extensive and it is the most updated rules as compared to the CPR and RC. This can be seen from several updates, amendments and writings 
on the FRCP since 2006 until the completion of this article.

\subsection{Discovery in the UK}

Part 31 of the CPR provides that a party discloses a document by stating that the document exists or has existed. This part limits disclosure to standard disclosure and its procedures. Rule 31.4 defines document as 'anything in which information of any description is recorded'. This definition is very broad and covers also electronic documents. However, after the amendment that came into force on $26^{\text {th }}$ April 1999 Practice Direction 31 that supplements Part 31 of CPR 1998 was inserted. This Practice Direction explains further on types of electronic documents and the process of electronic disclosure and inspection of documents [4].

The disclosure of electronic documents extends to disclosure of e-mails and other electronic communications, word processed documents and databases. Discovery of databases requires the identification of discoverable records that is relevant and necessary and there is a need to disclose only extracts of these records, not the entire database. Metadata and deleted documents are also discoverable.

Further, discovery of information is also allowed on the Internet service provider (ISP) and social network such as Facebook and Myspace. However, in Bunt $\mathrm{v}$ Tiley and others ${ }^{i v}$, the ISPs applied to strike out claims against them and no order for discovery was made. In this case, the ISP defendants (fourth to sixth) were claimed to be responsible for what have been posted on their website by their clients (first to third) and the claimants sought remedies against all of the defendants including the ISPs. The ISPs refused to be responsible and applied to strike out the claims against them. The court allowed their application. The refusal to allow for discovery is made when the ISP or other party thinks that the application for discovery is unreasonable and such disclosure may threaten their client's right and security.

In addition, under s2A.2 and s2A.3 of the Practice Direction to Part 31, parties are required to discuss any issues that may arise regarding searches for and the preservation of electronic documents before the first case management conference. The parties are also to co-operate at an early stage as to the format in which electronic copy documents are to be provided on inspection. The above provisions are very specific and provide a clear explanation about electronic documents.

\subsection{Discovery in Malaysia}

Order 24 of the RC provides on discovery and inspection of documents. This discovery is done by the court order at any stage of the proceedings. Rule 3 of Order 24 states that, the documents which a party to a cause or matter may be ordered to discover includes the documents in which the parties relies or will rely and the documents which could adversely affect his own case; adversely affect another party's case or support another party's case. There are several court forms that need to be filed and served by the applicant or a party requesting for discovery. The forms include Form 38 (List of documents), Form 39 (Affidavit verifying list of documents), Form 40 (Notice to inspect the documents), Form 41 (Notice to produce documents referred to in pleadings or affidavit) and Form 42 (Notice where the documents may be inspected). The list of documents must specifically state what documents believed to be in the possession, custody or power of the other party and whether the documents are privilege or not. After satisfying all the requirements the court will make order for discovery as in Form 43.

When the court makes an order for discovery the party so ordered is obliged to comply with it. However, the court order may be limited to certain documents or classes of documents and the order will only be granted if it is necessary and relevant to the cause or matter. The court will also order the production for inspection of any documents which in its opinion are necessary for disposing fairly of the cause or matter or for saving costs (Order 24 rule $13)^{\mathrm{v}}$. Thus, in case where there is a failure to comply with court order to make discovery of documents the case will be strike out. This happened in the case of Perbadanan Nasional Berhad v. Syed Omar Syed Mohamed $^{\text {vi }}$. Rule 16 of Order 24 further states that, in case any party is to make discovery of documents or to produce documents for the purpose of inspection or any other purpose fails to comply with the court order, then without prejudice the court may make such order as it thinks just including an order that the action be dismissed or, order that the defence be struck out and judgment be entered accordingly. The same rule also provides that the party who fails to comply with the court order is not allowed to refer to those documents except with the leave of the court. Nevertheless, this court order may be varied or revoked by a subsequent order or direction of the court.

However, the crucial point is Order 24 of the RC does not provide a specific Practice Direction on discovery of ESI and its procedure as in the UK. There is also no standard for e-discovery or best practices of e-discovery in Malaysian civil procedure. 


\subsection{Discovery in the US}

The law on discovery in the US is provided by the Federal Rule of Civil Procedure (F.R.C.P). But it is also controlled by the state rules. Generally, discovery in the US consists of depositions, discovery by interrogatories and Admission. After 2006, Rules 16, 26, 34 and Form 35 deal specifically with e-discovery and Rule 37 deals with Sanction. These new rules are intended to reduce the costs of discovery, to increase its efficiency, to increase uniformity of practice and to encourage the judiciary to participate more actively in case management. Rule 26 provides for general provisions governing Discovery and Duty of Disclosure. It also emphasises that the parties have an obligation to identify relevant electronic information in their initial disclosures to the opposing party and that the court and the parties discuss the preservation and disclosure of ESI at discovery planning conference i.e. parameters of their anticipated e-discovery. The parties must also agree on 'reasonable preservation steps' in conducting e-discovery.

Rule 26 provides details explanation on conducting e-discovery compared to CPR and RC 2012. Rule 26 provides for general provisions governing Discovery and Duty of Disclosure. This Rule covers the following matters:

(a) Required disclosures; Methods to Discover Additional Matter,

(b) Discovery Scope and Limits,

(c) Protective Orders,

(d) Timing and Sequence of Discovery,

(e) Supplementation of Disclosures and Responses,

(f) Conference of Parties; Planning for Discovery, and

(g) Signing of Disclosures, Discovery Request, Responses, and Objections.

Under Rule 26(a), the parties have an obligation to identify relevant electronic information in their initial disclosures to the opposing party. In addition, Rule 26(f) requires that the court and the parties discuss the preservation and disclosure of ESI at Rule 26 discovery planning conference i.e. parameters of their anticipated e-discovery. The parties must also agree on 'reasonable preservation steps' in conducting e-discovery, but prior to Rule 26(f) conference, the parties shall exchange the following information:

- A list of the most likely custodians of relevant electronic materials, including a brief description of each person's title and responsibilities,

- A list of relevant electronic systems that have been in place at all relevant times and a general description of each system, including the nature, scope, character, organization, and formats employed in each system. The limited accessibility of the electronic documents must also be stated;

- The name of the individual responsible for that party's electronic document retention policies;

- The name of the individual who shall serve as that party's 'e-discovery liaison',

- Provide notice of any problems reasonably anticipated to arise in connection with ediscovery. ${ }^{\text {vi }}$

The parties then will have to agree on the date to exchange the documents or to submit the issue for resolution by the court. Failure to abide by any court order or directions can result in sanctions being imposed. $^{\text {viii }}$ Thus, in the US, the court has a role to play in determining any dispute relating to ediscovery.

Apart from the FRCP there is also the US Civil Discovery Standards of the Federal Rules of Civil Procedure and E-discovery Best Practices. The standard of e-discovery in the US is that " any matter, not privileged, that is relevant to the claim or defense of any party" is discoverable as of right, and for good cause, the court may order that discovery of "any matter relevant to the subject matter involved in the action" be had.[5]

\section{What is e-discovery?}

Electronic discovery or e-discovery is a process of gathering information or data available in electronic format. The information is sometimes known as ESI. E-discovery is said to be a new way of recovering data and it is a powerful new litigation procedure. It also plays an important part in litigation because more information is available in the ESI and some lawyers have used this e-discovery method in their practice.

The practice of e-discovery is discussed in a famous US case of Zubulake v. UBS Warburg ${ }^{i x}$ where the plaintiff (employee) sued the defendant (her former employer) for gender discrimination and illegal retaliation. She claimed that the key evidence was available in various e-mails exchange among UBS employees which only existed on backup tapes and perhaps other archived media. She obtained an order compelling the employer (UBS) to produce those emails at its expense. The court took into consideration factors to balance the broad scope of discovery and the cost involved. After careful consideration, the court decided that the employer had to produce all responsive e-mails from the optical disks, backup tapes and other active servers at its own expense. The Honorable Judge Shira A. Scheindlin set seven factors for determination of cost-shifting and discovery costs. They are namely, (1) The extent to which the request is specifically tailored to discover relevant information; 
(2) The availability of such information from other sources;

(3) The total cost of production, compared to the amount at dispute;

(4) The total cost of production, compared to the resources available to each party;

(5) The relative ability of each party to control costs and their incentive to do so;

(6) The importance of the issues at stake in the litigation; and

(7) The relative benefits to the parties of obtaining the information. ${ }^{\mathrm{x}}$

However, there are advantages and disadvantages in implementing e-discovery. One of the advantages is e-discovery can still be conducted on encrypted document and deleted data by using special software through computer forensic examination while the disadvantage of e-discovery includes the high costs of implementing it. This happen to those who are not prepared. But these matters will not be mentioned in details in this paper. Only certain issues on ediscovery such as spoliation, privilege waiver and costs will be discussed.

\section{Issues on E-Discovery}

E-discovery is not a new thing in the US and the UK but it is quite a new practice in Malaysia. This explains why Malaysia has no precedent or rule of procedure on e-discovery and there is also no specific case on e-discovery process. However, the issues on conventional method of discovery of documents have been dealt with in many decided cases in Malaysia ${ }^{\mathrm{xi}}$. It is also a settled law in Malaysia that 'document' may also include electronic document or ESI. This is based on section 3 of the Evidence Act 1950 and the admissibility of computer output as evidence in Malaysia under sections 90A, 90B and 90C of the same Act.

According to section 3 of the Evidence Act 1950 (EA)(Malaysia)'document' refers to 'any matter expressed, described, or howsoever represented, upon any substance, material, thing or article, including any matter embodied in a disc, tape, film, sound track or other device whatsoever, by means of such as any sound recording, or any electronic, magnetic, mechanical or other recording whatsoever, by means of such as any sound recording, or any electronic, magnetic, mechanical or other recording whatsoever and howsoever made, or any sounds, electronic impulses, or other data whatsoever'. While section 29(1) and (2) of the Penal Code (Malaysia) defines 'document' as 'a matter recorded, stored, processed, retrieved or produced by a computer.'

From the procedural perspective, the RC 2012 defines the word 'document' as 'anything in which information of any description is recorded and includes a claim, summons, application, judgment, order, affidavit, witness statement or any other document used in a Court proceeding'. (Order 1 rule 4). This definition refers to the word 'information' which may include the ESI.

ESI includes electronic data or word processing files, encrypted documents and other electronic records. These days there are cases with trillions of bytes or terabytes. These bytes are available in electronic forms and they may be found in places like network servers, backup tapes, voicemail and email systems, disks, hand- held computerised personal organisers and personal home computers [6].The variety of these locations create more challenging environment to gather evidence.

As a result, issues on spoliation, privilege waiver, social media discovery, and sanctions on failure to comply with e-discovery request have become among the important issues in e-discovery process.

\subsection{Spoliation}

Spoliation is defined as the intentional alteration, destruction, or concealment of information that is relevant to pending or threatened litigation when a party knows or should know that the information is or may be relevant. In many cases, the American courts have found that mere negligence is enough to warrant sanctions.Thus, it is very important to preserve data which is relevant to the case. If the defendant failed to preserve ESI, delay their production of ESI, deleted or destroyed the evidence the court may decide such act as contempt of court. This can be seen in Victor Stanley, Inc v Creative Pipe, Inc, et.al, ${ }^{x i}$ when the Chief United States Magistrate Judge decided that a pervasive and willful violation of serial Court orders to preserve and produce ESI evidence be treated as contempt of court. This decision was made based on Fed. R. Civ. P.37 (b)(2)(A)(vii). It was further decided that the defendant may be imprisoned for a period not to exceed two years, unless and until he pays to Plaintiff the attorney's fees and costs that will be awarded to Plaintiff as the prevailing party pursuant to Fed. R. Civ. P. 37(b)(2)(C) . And severe sanction for spoliation was also granted on the defendant when the defendant lost the portable hard disk subsequent to the court's order to produce it ${ }^{\text {xiii }}$.

Violation of discovery is a serious issue. In $D L \mathrm{v}$ District of Columbia ${ }^{\text {xiv }}$ the Chief Judge imposed privilege waiver sanctions against the defendant for repeated discovery misconduct. The misconducts or violations include failure to timely produce documents, violation of multiple discovery orders, failure to timely provide a privilege log and failure to inform the court of any delays in production in order to request appropriate extensions [7]. In Furminator, Inc. v. Petvac Group LLC ${ }^{\mathrm{xv}}$, the district court also granted sanctions for repeated discovery misconduct 
by the defendant for willfully violated court orders on multiple occasions. Among them were consistent refusal by the defendant to abide by the docket control and discovery orders including failing to timely answer the complaint, failing to appear at the status conference, failing to produce any documents and many others. In addition, the e-mail was fraudulent and it was never sent by the defendant's counsel. The plaintiff's motion for striking out the defendant's pleading was granted and default judgment entered in favor of the plaintiff.

The US court has also granted a motion by the defendant to compel disclosure and preservation of the plaintiff's Facebook and MySpace information ordering the plaintiff to preserve his social media website pages and provide all passwords, usernames and log-in names for any and all MySpace and Facebook accounts to the defendant. Although the motion was objected by the plaintiff on the ground that the information was private and irrelevant the court disagreed with him [8].

\section{Managing Challenges in E-discovery}

The implementation of e-discovery is very challenging. For the US, what need to be achieved is to fulfill the mandate set forth in Rule 1 of the F.R.C.P, 'to secure the just, speedy, and inexpensive determination of every action and proceeding'. For this reason, the parties must not only fulfill the conditions of discovery the counsels must also know the technical aspects of discovering ESI, its cost and how to manage the ESI from its creation, maintenance and disposal [9]. He must also be able to distinguish between privilege document and non privilege document. However, if the plaintiff had mistakenly disclosed privileged documents he cannot then make a claim to recover all the documents previously disclosed to the defendants. In this regard, Vinelott $\mathrm{J}$ in Derby \& Co. Ltd $\mathrm{v}$ Weldon \& Others $\left(N_{o 10}\right)^{x v i}$ stated that the plaintiffs could not claim privilege in relation to the tape recording or the transcripts which had been inadvertently disclosed in the course of discovery. He further added that the defendants were entitled to assume that the documents included by the plaintiffs were documents which they proposed to rely on whether privilege or not.

\subsection{Unpreparedness}

In the UK even businesses including banks have also been criticised by the judges on their unpreparedness to produce ESI and cost sanction has been imposed on Earles v Barclays Bank Plc ${ }^{\text {xvii }}$. In this case, the judge made clear in the starkest terms that Practice Direction 31 2A (electronic disclosure) "is in the Civil Procedure Rules and those practising in the civil courts are expected to know the rules and practice them; it is gross incompetence not to". Costs consequences can flow from a failure to comply.

\subsection{Document retention policy}

Documents must be properly kept and managed as to avoid costly recovery of data. This is due to the reason that "e-discovery can only become a predictable, repeatable, and cost-effective business process if data is truly managed." It was further stated that cost predictability is the main driver in selecting an e-discovery solution. And there was also a statement stating that "e-discovery is not a legal problem; it is an IT problem"[10].

In addition, the businesses need to organise ESI properly in order to enable document search. By having complete document retention policy disputes arising from destruction of data can be avoided. But the challenge is to identify what documents need to be retained and for how long. Sometimes the data can be tampered or deleted. In the US, such disputes can lead to enormous monetary sanctions on those who are seen to have negligently failed to produce documents.[11] In this regard, the courts need to emphasise on transparency and reasonableness in the policies business adopt for the archiving and ultimate destruction of their ESI. It was also emphasised that parties need to properly organise their documents and adopt software that can search for documents and reduce number of documents that need to be reviewed. This method should be defensible methods by courts.

Apart from that employees also need to be educated and informed about the data retention policy and its provisions. They need to be trained as to how to retain the information and prepare the backup information. For business, internal trainings are needed if business wants to be ready for ediscovery of document. As to the judges, some of them are interested and seem to understand the ediscovery of ESI but they still need trainings as to familiarise themselves with e-discovery. The courts also need to set limits to the reasonable searches.

\subsection{Costs}

Since cost of e-discovery is the most challenging aspect parties to the action are encouraged to discuss and agree on the extent of reasonable search for document before undertake the search. By using this method parties can save cost for e-discovery and limit the process of e-discovery. In England and Wales, there are several court decisions on ediscovery of ESI which among others stress on the importance of limit to disclosure [12] and the importance to produce documents early [13]. It will be easier for lawyers if they have the check list of what are needed before searching for documents. By 
having consent between counsels and frank discussions about each party's electronic data system the proportional discovery can be conducted. This will avoid broad demands for discovery and save costs of discovery.

\subsection{Information management team}

Companies may also need to revisit and improve their information discovery strategies as to cope with the challenges in e-discovery. But the ongoing challenges are still there. One of them is the complexity of the case and the cost of e-discovery [14]. Other than that the cost of preservation of electronic data is also escalating. As to cope with the challenges there should be an Information Management Team which has four critically important responsibilities namely, implementation, education, enforcement, and compliance with company requirements, laws and regulations. A computer forensic expert should be appointed in the information management team. Besides performing his duties he can also play his role by persuading the other party to shift the cost of discovery. The computer forensic expert can assist in establishing the company's electronic document retention and deletion policy including the litigation hold policy, as well as offer advice on document storage and retrieval technology. During litigation the value of the computer forensic expert is very apparent. Further, the insights of the computer forensic expert can be very useful in formulating procedures governing the forensic inspection of computers and asking the right questions in the discovery process. The computer forensic expert can be invaluable in developing a persuasive argument in regard to shifting the costs of discovery to the adverse party in litigation. Another important benefit of having a computer forensic expert involved during litigation is educating the courts during the litigation process.

\subsection{Mistakes and misunderstanding}

But apart from relying on the computer forensic expert the counsels are also expected to have good knowledge in order to identify the common mistakes made by parties in relation to e-disclosure or ediscovery. This matter was highlighted by Master Steven Whitaker who has identified that the misunderstanding, the non understanding, reluctance and over reliance are some of the mistakes in ediscovery. This was evidence in several decided cases.

\section{The Possible Changes in Malaysia}

Based on the development and comments on ediscovery in the US, England and Wales it is submitted that e-discovery is still developing and will continue to develop until the rule becomes effective. It was even said that the amendment 'has not yet reached their full potential for effectiveness'. [15].The condemnation and criticism by some lawyers on e-discovery shall be taken positively. It is not really 'a nightmare' if one knows how to handle and develop e-discovery strategy. On the other hand, e-discovery prove to be working but more cooperation and more early planning as well as more knowledge of ESI are needed [16].

Hence, it is still not too late for Malaysia to adopt this method, to review the existing court rules and to introduce new practice direction as to ensure ediscovery can be implemented in Malaysia. Nevertheless, before planning for e-discovery the first thing that needs to be done is to create a response team comprising of information technology people, legal and departmental representatives.

Then, after determining whether litigation is actually likely, the team must decide what information must be preserved. Craig recommends requesting very specific information from the party filing the complaint to avoid spending money saving unrelated data [17]. However, until this date, there is still no effort made by the Malaysian lawyers to adopt e-discovery method. One of the reasons is because there is no governing rule and specific Practice Direction on e-discovery in Malaysia. Cost may also be one of the factors.

\subsection{Proactive approach}

But, even there is no rule on e-discovery, the law firms in Malaysia should take a proactive approach to e-discovery as this practice helps to reduce the time and costs associated with large e-discovery projects. This sounds very demanding but it is not impossible. In fact, in the US, as to help the lawyers to conduct a solid e-discovery Electronic Discovery Litigation packet was developed by the Exchange-working with leading American Association for Justice (AAJ) members. The packet covers discovery strategies, ethical concerns, preservation, spoliation, social networking sites, and other topics. Sample documents include preservation letters, requests for production, a preservation motion, and court orders [18].

Other than that, Electronic Discovery Reference Model (EDRM) was also created in May 2005 to address the lack of standards and guidelines in ediscovery market [19]. Not only that the judiciaries have also been encouraged to learn and be aware of e-discovery and its relevant issues. In US for instance, the Institute for the Advancement of American Legal System (IAALS) have recently conducted trainings on e-discovery for the judges ${ }^{\text {xviii }}$. The aim of the training is to equip the judges with 
knowledge on e-discovery and how to manage it effectively. Perhaps the Malaysian judges also need trainings as to understand the e-discovery process. The above recommendations are important for Malaysian lawyers and the judges because they need to react to modern technology and use e-discovery of ESI in the future.

\section{Conclusion}

It is no doubt that in future more data will be in stored electronically and there will be more challenges ahead. By looking at the decided cases in the US and the UK it is obvious that issues pertaining to e-discovery and production of documents will continue to challenge the implementation of e-discovery of ESI. Nevertheless, it is still not easy to achieve comprehensive and reliable e-discovery in a short time since parties need to be ready and have proper planning before adopting e-discovery. However, it is still one of the best methods of gathering information since it is time saving, relieving the burden of preparing hard copies of various documents and maintaining the integrity of the evidence. The efforts taken by the US and the UK in amending the rule on discovery of ESI should be praised. It is hoped that the Malaysian civil procedure will be reviewed again after the enforcement of RC 2012 in August as to include specific Practice Direction on e-discovery of ESI.

\section{Acknowledgements}

Thank you to my research assistant, $\mathrm{Mr}$ Sharaffuddin for assisting me in finding the materials for this research.

\section{References}

[1] Luoma, Vicki Miller. (2006) 'Computer forensics and electronic discovery: The new management challenge', Computers \& Security (25), pp. 91-96.

[2] Menzies J in Mulley v Manifold (1959) 103 CLR 341 at 345 and Banque Cantonale Vaudoise v Fujitrans (Singapore) Pte Ltd [2007] 1SLR 570. See also Kenneth J. Withers, Computer - based disclosure and discovery in civil litigation, Journal of Information Law and

Technology (JILT); http://elj.warwick.ac.ukljiltiOI1/withers.htnl (20 December 2011)

[3] Malaysian Court Practice: High Court, Practitioner edition, Malaysia: MLJ, 2007.

[4] No OS-C-S2S (E.D.wis. Apr, 20, 2011)

[5] Anderson, Daniel M., 'Benefits of implementing ediscovery best practices' in E-discovery best practices United States: Aspatore, 2008, at p.12.
[6] Callcott, John R., \& Hulett, Eric J., 'Electronic discovery: Pitfalls and possibilities,'(April 29, 2004); http://www.martindale.comllitigationlaw/ article_Steptoe-Johnson-PLLC_67994.htrn ( 2 March 2012)

[7] Backhouse, Denise E., 'Chief Judge imposes privilege waiver sanctions against defendant for repeated discovery misconduct in DL $\mathrm{v}$ District of Columbia', National Law Review; http://www.natlawreview.com (13 February 2012)

[8] Zimmermann v. Weis Markets Inc, No. CV-09-1535 (Comm. Pleas Ct., Penn. May 19, 2011)

[9] Whitaker, Steven., "International Development in E Discovery", International Conference on Electronic Litigation, Singapore, August 2011.

[10] Boeri, Robert.,(2010) 'E-discovery: Your Next nightmare', EContent (33.8):15; http://search.proquest.com/socialsciences/ (23 February 2012)

[11] Darigan, Melissa E., "ESI Management and eDiscovery: Successful strategies" in 'E-Discovery Best Practices' , United States: Aspatore, 2008, pp.55-60

[12] Goodale v The Ministry of Justice, 2009] EWHC B41 (QB) $\left(5^{\text {th }}\right.$ November 2009)

[13] Bond v Dunster Properties [2011] EWCA Civ 455 (CA) 21st April 2011.

[14] Davis Khoo, Nancy., (2009) 'Search for success: Information Discovery in the effective enterprise,'. Econtent; www.econtentmag.com (4 May 2011)

[15] Milberg \& Hausfeld, E-discovery today: The fault lies not in our rules... The Federal Courts Law Review 2011 vol4 Issue 2, at 14

[16] Rogers, Douglas L., A search for balance in the discovery of ESI since December 1,2006, 14 RICH. J.L. \& TECH. 8;

http://law.richmond.edu/jolt/v14i3/article8.pdf.(10 January 2012)

[17] 'E-discovery costs are high for the unprepared', $E D$ Brock. The American City \& County. Pittsfield: Dec2010. Vol. 125, Iss. 13; pg. 12

[18] Unsure about e-discovery Anonymous. Trial. Washington: United States, Sept 2010, Vol. 46, Iss. 9; pg. 44; http://www.proquest.umi.com (3 March 2011)

[19] EDRM;

http://edrm.net/files/Frequently_Asked_Questions.pdf (24 May 2012) 
${ }^{\mathrm{i}}$ In Malaysia, the power to gather information is mentioned under Part $\mathrm{V}$ of the Communications and Multimedia Act 1998. (CMA) This power is bestowed upon the Malaysian Communications and Multimedia Commission (MCMC) under section 73 of the CMA. It provides among others that the Commission may direct any person to give information and to produce it when directed.

ii In Thermal Design, Inc v. Guardian Building Products, Inc.,.No 08-C-828 (E.D Wis. Apr,20,2011) the U.S District Court Judge Rudolph T. decided that disproportionate request by the plaintiff for the ESI hold for the ESI hold by the defendant was amount to fishing expedition and that the defendant had met its burden under the Federal Rule of Civil Procedure(F.R.C.P 26(b)(2)(C)).

iii ABX Logistics (Malaysia) Sdn Bhd v Overseas Bechtel (Malaysia) Sdn Bhd [2003] 7 CLJ 357.

iv 3 All ER 336; [2006] EWHC 407 (QB) .

${ }^{v}$ See Rotta Research Laboratorium Spa \& Another v Ho Tack Sien \& Ors [2010] 10 CLJ

vi [2011]1 LNS 96

vii See Default Standards for discovery of electronic documents ("e-discovery").

http://www.ded.uscourts.gov/SLR/Misc?Ediscov.pdf (25 August 2012).

viii Mosaid Technologies Incorporated v. Samsung Electronic Co., Ltd., Samsung Electronics America, INC., Samsung Semiconductor, INC., and Samsung Austin Semiconductor 2004 U.S. Dist. LEXIS 25286. ${ }^{i x} 229$ F.R.D. 422 (S.D.N.Y 2004)

${ }^{x}$ The court rejects two of the Rowe Entertainment's factors and creates seven new factors to determine whether cost shifting should occur. See Rowe Entertainment, Inc v Wm. Morris Agency, Inc., 205 F.R.D (S.D.N.Y. 2002). In Rowe's case the court considers eight factors when allocating costs of electronic discovery; http://www.forensics.com/html/resource-case-mustread.html ( 15 August 2012)

${ }^{x i}$ See for example cases of Yekambaran Marimuthu v Malayawata Steel Berhad [1994] 2 CLJ 581 at 585. (HC, Penang), [1993] MLJU 96 (unreported); Manilal \& Sons (Pte) Ltd v Bhupendra KJ Shan ( $t$ / a JB International [1990] 2 MLJ 282 at 288 and ABX Logistics (Malaysia) Sdn Bhd v Overseas Bechtel (Malaysia) Sdn Bhd [2003] 7 CLJ 357

xii Civil No.MJG-06-2662 (D.Md.sept.9,20100 (affirmed by the U.S District Court with an Order for Mr. Pappa to pay the remaining $\$ 571,440$ balance of the $\$ 1$ million sanctions award)

xiii $Y u$ Chen v. $L W$ Restaurant, Inc., et.al, No $10 \mathrm{CV}$ 200 (ARR) (E.D.N.Y. Aug.3, 2011).

xiv Backhouse, Denise E., Chief Judge imposes privilege waiver sanctions against defendant for repeated discovery misconduct in DLv District of Columbia, the National Law Review, http://www.natlawreview.com (Access Date:13 Feb, 2012)

Case No. 2-08-cv-338-TJW (E.D.Tex. Aug 5, 2011)

xvi [1991] 2 All ER 901

xvii ( [2009] EWHC 2500)

xviii Satrom, Meg., (July 30, 2012) 'Arming judges to combat e-discovery battles', Law Week Colorado, Vol. 10, No.31

http://www.LAWWEEKONLINE.com 